\title{
Teaching English Pronunciation Online during the COVID-19 Crisis Outbreak
}

\section{Leticia Quesada Vázquez}

Department of English and German Studies, Rovira i Virgili University, Tarragona, Spain.

\begin{abstract}
The abrupt emergence of the COVID-19 pandemic in spring 2020 forced tertiary professors to urgently adapt the face-to-face courses they were lecturing to emergency remote teaching. Researchers of different fields have started to investigate and share their thoughts on which are the best methodologies to guarantee a high-quality learning experience while coping with students' anxiety and teachers' lack of technical background. The present study examines the adaptation of an English pronunciation course at Rovira $i$ Virgili university to the online setting imposed by the outbreak of the pandemic. The students who took the course were asked to fill in a satisfaction survey containing multiple choice, Likert scale and open questions on the different measures taken and the general progress of the course. Results show that students were higly satisfied with the adaptation of the course to the online context, and that the methods adopted and tools provided were useful and sufficient to continue with the adequate functioning of the course. Hence, this study is a sample of how to teach pronunciation remotely in particular, and how to successfully adapt a face-to-face university course to emergency remote teaching in general, guaranteeing students' learning and engagement.
\end{abstract}

Keywords: Pronunciation teaching; emergency remote teaching; online learning; English as a foreign language teaching. 


\section{Introduction}

The outbreak of the COVID-19 pandemic has become one of the greatest defies of lastcentury tertiary professors worldwide. The sudden lockdown and the still existing preference towards telecommuting to battle the pandemic have obliged teachers to reconsider and redesign the courses they teach in record time so as to adapt to an unprecedent and imminent need for virtual education (Bao, 2020; Hodges et al, 2020; Moser, Wei \& Brenner, 2021; Rahiem, 2020; Rapanta et al., 2020). Although the existence of emergency remote teaching, i.e. the temporary adaptation of traditional face-to-face courses to an online setting because of a crisis (Hodges et al, 2020) is not a new concept, its lack of anticipation due to the abrupt emergence of the COVID-19 pandemic forced teachers to change their teaching methods and approaches almost overnight (Rahiem, 2020). Indeed, a lack of initial technical support together with a scarce knowledge of desinging and facilitating successful learning experiences online have made of this adaptation to remote teaching a real challenge for many of them (Bao, 2020; Monser et al., 2021; Rapanta et al., 2020). As the duration of remote teaching due to COVID-19 remains unknown, the research community has thrown themselves into finding applicable solutions that guarantee high-quality learning experiences.

To the author's knowledge, no studies concerning the teaching of English pronunciation to nonnative speakers during the COVID-19 crisis outbreak have been published yet. Despite the fact that nowadays there are several free resources online that can help students improve their pronunciation in English (see Calvo Benzies, 2017; O-Brien et al., 2018; Walker, 2014 for a review), how their use and combination can guarantee prosperous pronunciation instruction in an emergency remote teaching context still needs to be studied. As a first approach to fill this gap, the current study aims at examining how successful the adaptation of an original face-to-face pronunciation course to an online setting was in order to cope with the COVID-19 pandemic crisis. To this end, the study attempts to address the following research question:

R.Q. To what extent were the measures adopted to adapt the pronunciation course to an online setting satisfactory to guarantee an adequate learning process?

In order to give response to this question, a satisfaction survey was designed and sent to thirdyear English undergraduates taking a pronunciation course at Rovira i Virgili University (Tarragona, Spain) during the 2019-2020 academic year. Students were mainly enquired about the organization of the course and the teaching activities adopted. The questionnaire was made up of multiple choice, Likert scale and open questions that gathered information about their thoughts on different aspects related to the arrangements performed. 


\section{Methodology}

\subsection{Participants}

From the 48 enrolled students, 16 participated in the study, 11 women and 5 men. Only 2 of the women were taking the course for the second time; for the rest of the participants it was their first time studying the subject. All of them were in their twenties (6 students were 20;5 of them, 21; and 4 of them, 22), except for one of the women retaking the course who was 40. Regarding their nationalities, participants were mainly Spanish (10 students), but there were also students coming from other European countries (1 Birtish, 1 Irish and 1 Bulgarian), Arab countries (1 Moroccan, 1 Algerian), and South American countries (1 Peruvian). However, only the British woman was an Erasmus student who did not have a high command of either Spanish or Catalan; the rest of them were natives in one or the two languages, since they were either born or raised in Catalonia.

\subsection{Adaptation of the course}

Sound System II is a phonetics and phonology course aimed at learning how to transcribe in English and improving English undergraduates' pronunciation. Before taking this course, students have to take Sound System I during the first semester, where they start learning how to transcribe phonemes in English and practice how to produce vowel sounds. By contrast, Sound System II focuses on the practice and transcription of consonant allophones and suprasegmental features, such as rhythm and intonation. During the academic course 20192020, students took Sound System I entirely at university, while they could just take the first part of Sound System II in class, i.e. consonant instruction; the rest of the course, mainly concentrated on suprasegmentals, had to be taken from home due to the COVID-19 lockdown. At that time, no continuous assessment exams had already been taken, so the adaptation of the subject to an online setting implied facing important challenges as far as instruction and evaluation were concerned (see Table 1).

A mixture of synchronous and asynchronous teaching was adopted: Theory letures were substituted by weekly PowerPoint presentations on which the teacher recorded her explanations. Students were asked to watch and listen to the PowerPoint document during the week and ask questions or doubts through the Moodle's forum, where both the teacher and the students could participate in the discussion. Regarding practice sessions, the teacher recorded herself pronouncing the exercises out loud while providing tips to improve their pronunciation. Students had to watch the videos to practice for their recording submissions and the oral test. On the other hand, the teacher taught students to transcribe with their computers using a free online transcription tool called Type It (https://ipa.typeit.org/full/). Students were asked to transcribe a series of sentences and words every week and send it to the teacher before Friday: the teacher chose some of the exercises from different students and 
recorded a PowerPoint presentation correcting them and explaining the different mistakes. On Friday, students were asked to watch the PowerPoint presentation and connect to an online meeting where students could ask the teacher about their doubts on both the practice and the theory they had worked on. Besides, during the online meetings the teacher provided support form them to keep up with the course and encourange them not to give up.

Table 1. Measures taken to adapt the course to an online setting.

\begin{tabular}{llll}
\hline \multicolumn{1}{c}{ Theory } & Practice & Assessment \\
\hline $\begin{array}{l}\text { In- } \\
\text { person }\end{array}$ & Theory Lectures & Production and & 3 written exams (T1: 20\%; T2: 10\%; T3: 15\%) \\
& & transcription & 1 oral test $(15 \%)$ \\
& exercises & 10 recordings $(25 \%)$ \\
& & Attendance $(5 \%)$ \\
& & Participantion $(10 \%)$ \\
\hline Online & Narrated & Production: & Passing grade: $60 \%$ \\
& PowerPoint & Videos & 1 oral test $(15 \%)$ \\
& presentations & Transcription: & 10 recordings $(25 \%)$ \\
& & Online & Attendance $(5 \%)$ \\
& & transcription & Participantion $(10 \%)$ \\
& keyboard; & Passing grade: $50 \%$ \\
& PowerPoint & \\
& presentations & \\
\hline
\end{tabular}

Regarding the assessment, the original plan was maintained as much as possible, but some rearrangements had to be made: The three tests became just one final test that had to be taken online via a Moodle questionnaire so as to give students time to adapt to the new learning context. It included theory questions, analytical questions where students had to identify and explain transcription issues, and the transcription of a text using Type It; the oral test was carried out via videoconference; the recordings continued being submitted via Moodle on the original dates; the attendance grade was made up of their weekly interaction with the PowerPoint presentation, and their attendance to the online meetings; participation was assessed by the submission of the transcription exercises and their interaction in the forum. In addition, the passing grade was lowered to a $50 \%$ from its intial $60 \%$ to cope with the anxiety the setting changes were causing to the students and compensate their fast adaptation to use online tools they were not supposed to employ for the original course.

Table 2. Students' academic performance (\%).

\begin{tabular}{cccccc}
\hline & Excellent & Notable & Pass & Fail & Non-assessable \\
\hline SSII 19-20 & 4.35 & 21.73 & 36.95 & 13.04 & 23.91 \\
SSII 18-19 & 1.72 & 12.07 & 39.66 & 32.76 & 13.79 \\
\hline
\end{tabular}


As displayed in Table 2, the measures taken did not negatively affect the students' academic performance: Compared to the previous year, the number of students who took the continuous assessment and failed the couse dropped, and the number of learners who achieved an excellent or a notable grade rose. The number of students who did not follow the assessment increased a $10.15 \%$, but only one student withdrew due to the pandemic.

\subsection{Survey}

The survey was designed using Google Forms and sent to the participants once the final grades were published via the message board of the course's Moodle space. Students were informed about the willingness to use the results of the questionnaire for research purposes and they participated voluntarily and anonymously. The survey consisted of eight different sections: background information, theory lectures, practice sessions, extra activities, exam training session, assessment of the course and general opinion on their experience with online learning. The four first questions were used to outline the participants' profile, while the others were examined to analyze their opinions on the virtual adaptation of the course.

On sections 2-5, students answered the same questions for the different measures adopted: a yes-no question about how satisfactory was the use of that element to adapt the course to the online setting; a 5-point Likert scale evaluating the usefulness of the element; and two more yes-no questions asking whether that measure was enough and whether there could have been better measures to be taken. Two open questions were also included so that students could justify their answers when they thought the item had not been a good option and recommend possible alternatives. On the other hand, sections 6-8 focused on the course assessment and the general learning process. Section 6 examined the additional supporting material: via yesno and open questions, learners were enquired about whether they found the extra activities used motivating and they could suggest other activities to enhance motivation. On section 7 students had to answer several yes-no questions about the adaptation of the assessment and justify their answers. Finally, section 8 contained yes-no questions regarding technological difficulties they may have experienced and whether they felt demotivated and willing to drop out during the course, and two 5-point Likert scale questions on their global satisfaction on the course and its virtual adaptation.

\section{Findings and discussion}

As far as theory is concerned, all the ones polled found the narrated PowerPoint presentations a satisfactory tool to adapt the theory lectures to the online setting. As displayed in Table 3, they considered them higly helpful $(M=4.56 ; S T D=0.61)$. Although all of them thought these were enough to keep up with theory, two students suggested that it would have been useful to have some virtual classes to further explain some of the concepts tackled, or include exercises where the theory was applied to sharpen their reasoning skills. 
Table 3. Means $(M)$ and standard deviations (STD) of the 5-point* Likert scale question: "How helpful was the tool to keep learning from the course?" on sections 2-4.

\begin{tabular}{|c|c|c|c|c|c|c|c|c|c|c|c|c|}
\hline \multirow{2}{*}{$\begin{array}{c}\text { Theory } \\
\text { Narrated } \\
\text { PowerPoint } \\
\text { Presentations }\end{array}$} & \multicolumn{5}{|c|}{ Practice } & \multicolumn{7}{|c|}{ Doubt-Solving } \\
\hline & & $\begin{array}{c}\text { Transcription } \\
\text { exercises }\end{array}$ & t & $\begin{array}{l}\text { PowerPoint } \\
\text { transcription } \\
\text { correction }\end{array}$ & & $\begin{array}{l}\text { Weekly } \\
\text { Online } \\
\text { meetings }\end{array}$ & & $\begin{array}{l}\text { Moodle's } \\
\text { Message } \\
\text { board }\end{array}$ & $\begin{array}{l}\text { Moodle's } \\
\text { forum }\end{array}$ & & $\begin{array}{r}\text { Ema } \\
\text { communi }\end{array}$ & ation \\
\hline$S T D$ & $M$ & $S T D$ & $M$ & $S T D$ & $M$ & $S T D$ & $M$ & $S T D$ & $M$ & $S T D$ & $M$ & $S T D$ \\
\hline 0.61 & 4.27 & 0.68 & 4.13 & 0.48 & 4.4 & 0.61 & 4.13 & 0.88 & 4 & 0.87 & 4.69 & 0.58 \\
\hline
\end{tabular}

Regarding practice, 15 out of the 16 learners enquired considered that the transcription submissions were a suitable method to practice transcription. However, the one who did not agree explained: "I think they were, but the time to hand them in was not enough." Students had to submit their exercises by Thursday so that the teacher could prepare the PowerPoint presentation with the corrections for Friday morning. As students also had to work on other courses during the week, perhaps they would have appreciated to also have the weekend to complete the exercises. However, they still found them highly benefitial $(M=4.27 ; S T D=$ 0.68). As for the PowerPoint presentations with the corrections of the transcriptions, all of them thought they were satisfactory and very helpful $(M=4.13 ; S T D=0.48)$.

Due to the general uncertaintity that the COVID-19 crisis caused, it was also important to evaluate the teacher-learner communication. All the students believed that the online meetings, the Moodle's message board and forum, and email correspondence were adequate tools to solve doubts and guarantee communication. As shown in Table 3, all the different measures had a mean of 4 or above, which means that students found these tools very useful. Although there was one student who answered there could have been better alternatives to solve doubts, that person did not specify which ones.

The exam training session was analyzed separately on section 5. An online meeting was conducted to explain the different parts the exam would contain, and practice the transcription of a text using the online keyboard. Although 15 out of 16 of the participants though it was a satisfactory tool to practice for the exam and a highly useful approach on average $(M=4.2$; $S T D=0.75^{1}$ ), some students thought that they would have liked to have another session and practice other exam exercises apart from transcription.

As for the the extra activities, the rhythm questionnaire was highly rated; it was not only considered motivating by $81.25 \%$ of the students, but $100 \%$ of the learners who answered

\footnotetext{
${ }^{1}$ 5-point Likert scale scale question ( 0 being “not at all”, 5 being “very useful”): "How helpful was the exam training session to practice for the exam?"
} 
the question also considered it a useful tool for self-assessment. When asked if they would like to have more extra activities like the ones used, $87.5 \%$ replied they would.

Regarding the course assessment, all the students considered that the evaluation of the course had been adapted successfully to the online situation. In addition, 15 out of 16 of the participants thought that the written exam met the requirements of the course and there were no better alternatives provided. The person who did not agree just said that there were better applications to carry out the meetings. However, the application to use was not chosen by the teacher, but provided by the institution.

When enquired about more general issues, $31.25 \%$ of the students claimed that they experienced technological problems. Some of them stated that their equipment was not powerful enough and had to buy a new computer, or that their Internet connection at home was limited. The same amount thought that online learning could have negatively affected their performance in the course: some of them explicitly said that they thought they learn more and they can retain more information in face-to-face sessions. In fact, $37.5 \%$ confessed that they felt demotivated and willing to drop out at some point during the course. Among the reasons, many of them claimed episodes of anxiety: "Sometimes I couldn't follow the course as much as I would in class because I experienced some bad weeks of anxiety and nerves due to lockdown;" "Because it was not easy to work from home with all the things happening. I felt like more pressure." However, 60-70\% of the participants followed the course without suffering from either technological or emotional breakdowns. Besides, all the students were highly satisfied with the adaptation of the course to the online setting $(M=$ 4.44; $S T D=0.61)$ and the course itself $(M=4.34 ; S T D=0.7)^{2}$.

\section{Conclusion}

Besides the fact that students' results showed a satisfactory academic performance despite remote learning, learners believed that the pronunciation course was successfully adapted to the demands of the situation: both theory and practice tools and methods were considered highly useful to keep up with the course in spite of the emotional distress caused by the abrupt emergence of the COVID-19 pandemic. According to the teacher, the success of the implementation of remote learning in this course might have been thanks to a willingness to balance both synchronous and asynchronous teaching and modifying just those aspects of the original teaching plan that were not doable online, trying to maintain its initial framework. In addition, students were taught how to use the new digital tools that they needed to continue with the normal progress of the subject and their needs and doubts were listened to, offering

\footnotetext{
2 5-point Likert scale scale questions ( 0 being "not at all", 5 being "very satisfied"): "How satisfactory was the adaptation of the course to an online setting?" "From a global perspective, how satisfied are you with this course?"
} 
them support and solutions to their problems (Moser et al. 2021). However, as remote teaching will continue being the general rule during the 2020-2021 academic year, it would be interesting to study whether synchronous transcription practice is maneageable, especially for those courses where students have no previous knowledge on how to transcribe. On the other hand, some of the activities, tools and teaching methods adopted could still be used when resuming face-to-face lectures: for instance, students might still find video practice or pre-test review questionnaires helpful to practice on their own. Moreover, online tools could offer those students who cannot attend classes regularly due to labor or medical reasons the opportunity to follow the course remotely. This study, hence, should be seen as an initial roadmap for practitioners who now face the setbacks of teaching pronunciation remotely, and who will have to keep readjusting their methods to the digital transformation higher education is experiencing, which has come to stay.

\section{References}

Bao, W. (2020). COVID-19 and online teaching in higher education: A case study of Peking University. Human Behavior and Emerging Technologies, 2(2), 113-115. doi: 10.1002/hbe2.191

Calvo Benzies, Y.J. (2017). Contributions of new technologies on the teaching of English pronunciation. Language Value, 9(1), 1-35. Jaume I University ePress: Castelló, Spain. doi: 10.6035/LanguageV.2017.9.2

Hodges, C., Moore, S., Lockee, B., Trst, T., \& Bond, A. (2020). The difference between emergency remote teaching and online learning. Educause Review. https://er.educause.edu/articles/2020/3/the-difference-between-emergency-remoteteaching-and-online-learning

Moser K.M., Wei, T. \& Brenner, D. (2021). Remote teaching during COVID-19: Implications from a national survey of language educators. System, doi: 10.1016/j.system.2020.102431

O-Brien, M. G., Derwing, T. M., Cucchiarini, C., Hardison, D. M., Mixdorff, H., Thomson, R. I., Strik, H., Levis, J. M., Munro, M. J., Foote, J. A., \& Levis, G. M. (2018). Directions for the future of technology in pronunciation research and teaching. Journal of Second Language Pronunciation, 4, 182-206. doi: 10.1075/jslp.17001.obr

Rahiem, M. (2020). The emergency remote learning experience of university students in Indonesia amidst the COVID-19 crisis. International Journal of Learning, Teaching and Educational Research, 19(6), 1-26. doi: 10.26803/ijlter.19.6.1

Rapanta, C., Botturi, L., Goodyear, P., Guàrdia, L. \& Koole, Maguerite (2020). Online university teaching during and after the COVID-19 crisis: Refocusing teacher presence and learning activity. Postdigit Sci Educ, 2, 923-945. doi: 10.1007/s42438-020-00155-y

Walker, R. (2014). Technology for pronunciation. English Teaching Professional, 95, 2931. https://englishglobalcom.files.wordpress.com/2014/03/technology-forpronunciation-etp-95.pdf 